\title{
Quantitative analysis of $\mathbf{O}^{6}$-methylguanine DNA methyltransferase (MGMT) promoter methylation in patients with low-grade gliomas
}

\author{
Adrian F. Ochsenbein • Adrian D. Schubert • \\ Erik Vassella $\cdot$ Luigi Mariani
}

Received: 3 February 2010/Accepted: 31 August 2010/Published online: 21 September 2010

(C) Springer Science+Business Media, LLC. 2010

\begin{abstract}
Methylation of the MGMT promoter is supposed to be a predictive and prognostic factor in glioblastoma. Whether MGMT promoter methylation correlates with tumor response to temozolomide in low-grade gliomas is less clear. Therefore, we analyzed MGMT promoter methylation by a quantitative methylation-specific PCR in 22 patients with histologically verified low-grade gliomas (WHO grade II) who were treated with temozolomide (TMZ) for tumor progression. Objective tumor response, toxicity, and $\mathrm{LOH}$ of microsatellite markers on chromosomes $1 \mathrm{p}$ and $19 \mathrm{q}$ were analyzed. Histological classification revealed ten oligodendrogliomas, seven oligoastrocytomas, and five astrocytomas. All patients were treated with TMZ $200 \mathrm{mg} / \mathrm{m}^{2}$ on days $1-5$ in a 4 week cycle. The median progression-free survival was 32 months. Combined LOH $1 \mathrm{p}$ and $19 \mathrm{q}$ was found in 14 patients; one patient had LOH $1 \mathrm{p}$ alone and one patient LOH 19q alone. The LOH status could not be determined in two patients and was normal in the
\end{abstract}

Back to back submission: Erik Vassella et al. Primer extension-based quantitative polymerase chain reaction reveals consistent differences in methlyation status of the MGMT promoter in diffusely infiltrating gliomas (WHO grade II-IV) of adults.

A. F. Ochsenbein $(\varangle) \cdot$ A. D. Schubert

Department of Medical Oncology, University Hospital Berne, Berne 3010, Switzerland

e-mail: adrian.ochsenbein@insel.ch

E. Vassella

Institute of Pathology, University of Berne, Berne 3010,

Switzerland

L. Mariani

Department of Neurosurgery, University Hospital of Basel,

Basel 4031, Switzerland remaining four. $\mathrm{LOH} 1 \mathrm{p}$ and/or $19 \mathrm{q}$ correlated with longer time to progression but not with radiological response to TMZ. MGMT promoter methylation was detectable in 20 patients by conventional PCR and quantitative analysis revealed the methylation status was between 12 and $100 \%$. The volumetric response to chemotherapy analyzed by MRI and time to progression correlated with the level of MGMT promoter methylation. Therefore, our retrospective case series suggests that quantitative methylation-specific PCR of the MGMT promoter predicts radiological response to chemotherapy with TMZ in WHO grade II gliomas.

Keywords Low-grade glioma - Temozolomide · MGMT promoter $\cdot$ LOH $\cdot$ Chemotherapy

\section{Introduction}

Low-grade gliomas are slow-growing tumors that have a peak incidence around age 40 years. Maximum feasible resection is the treatment of choice, despite the lack of randomized trials supporting that concept. Although extended survival after resection is typical, most patients eventually succumb to recurrent disease. Upfront adjuvant radiation therapy (RT) modestly improves progression-free survival but not overall survival compared with RT delayed until recurrence [1], and application of doses of 59.4 Gy or higher is no more effective than doses as low as $45 \mathrm{~Gy}$ $[2,3]$. On the basis of on this evidence and because of concerns about the potential long-term neurotoxicity of RT this treatment is usually delayed until recurrence [4, 5]. Chemotherapy with oral temozolomide has clearly become a treatment option for WHO grade II glioma patients [6-10], with excellent response rates, especially in oligodendroglial tumors, which typically show loss of 
heterozygosity of chromosomes $1 \mathrm{p} / 19 \mathrm{q}[9,10]$. TMZ and RT are currently being compared in a multicenter, randomized trial (EORTC 22033, 26033). In fact, it is unclear when and how to incorporate chemotherapy into the treatment strategy for low-grade gliomas. Molecular markers may help in selecting patients who are likely to benefit from chemotherapy. LOH $1 \mathrm{p} / 19 \mathrm{q}$ helps to predict response to chemotherapy; it is, however, also a prognostic marker in the absence of chemotherapy [11, 12] and the genes and signaling pathways that are associated with this loss are yet to be determined.

TMZ is a pro-drug that, when hydrolyzed, modifies the DNA at several sites, most commonly generating $N^{7}$ methylguanine and $N^{3}$-methyladenine, which constitute nearly $90 \%$ of the total methylation events, and to a lesser extent $\mathrm{O}^{6}$ methylation events. Despite the fact that $\mathrm{O}^{6}$-methylguanine accounts only for about $5 \%$ of all methylation events, adducts at the $\mathrm{O}^{6}$ position of guanine are particularly mutagenic and cytotoxic, and probably responsible for the cytotoxic effect of TMZ [13]. $\mathrm{O}^{6}$-Methylguanine methyltransferase (MGMT) is a DNA-repair protein that rapidly reverses alkylation (including methylation) at the $\mathrm{O}^{6}$ position of guanine, thereby neutralizing the cytotoxic effects of alkylating agents such as TMZ. High levels of MGMT activity in tumor tissue are associated with resistance to alkylating agents [14]. MGMT gene silencing by promoter methylation results in reduced MGMT expression in tumor cells, and therefore, MGMT promoter methylation is associated with longer survival of glioblastoma patients treated with TMZ. However, MGMT promoter methylation is also a prognostic factor in the absence of adjuvant chemotherapy with alkylating agents $[15,16]$. Other authors have shown that a multigene profile may be superior to MGMT methylation status in predicting response to TMZ in glioblastoma patients and that MGMT status did not significantly correlate with overall survival in multivariate analysis [17]. The role of MGMT activity in predicting response to chemotherapy in low-grade gliomas is even less clearly established.

Several methods for measuring MGMT levels within tumors have been described (reviewed elsewhere [18]). The MGMT protein can be detected in tissue samples by immunohistochemistry, enzyme activity can be measured by high-performance liquid chromatography (HPLC), and epigenetic silencing of the MGMT gene by promoter methylation can be assessed by using a methylation-specific polymerase chain reaction assay. We performed a retrospective study to analyze the correlation between MGMT promoter methylation, radiological response, and time to progression in a series of WHO grade II glioma patients treated with TMZ. The MGMT methylation status was assessed using a primer extension-based quantitative polymerase chain reaction.

\section{Materials and methods}

\section{Patients}

Patients with WHO grade II glioma, diagnosed at our institution between 1989 and 2007 and treated with TMZ between 1999 and 2007, were included into this retrospective study. Patients with radiological signs of progression to high grade gliomas (e.g., a new contrast enhancing lesion) at start of TMZ treatment were excluded.

\section{Outcome}

Magnetic resonance images (MRI) were obtained before therapy and every six months thereafter. Digitized MRIs were analyzed using Sectra IDS5 10.2 Software (Sectra Imtec, Linköping, Sweden). Tumor volumes were measured on the basis of the entire region of hyperintensity (compared with normal brain) in T2-weighted and FLAIR MRIs. Tumor response was defined as minor (MR, reduction by $\geq 25$ to $<50 \%$ of the initial tumor volume), partial ( $\mathrm{PR}, \geq 50 \%$ ), and complete ( $\mathrm{CR}$, no residual tumor). Progressive disease was defined as an increase in tumor volume by $\geq 25 \%$, independent of contrast enhancement.

\section{DNA extraction}

Representative areas of the tumor were excised from formalin-fixed paraffin-embedded tissue and DNA was extracted using the EZ1 tissue kit (Qiagen, Hombrechtikon, Switzerland) according the manufacturer's procedure. Tissues were heat-treated in lysis buffer for $10 \mathrm{~min}$ at $95^{\circ} \mathrm{C}$ prior to proteinase $K$ digestion. Reference DNA was extracted from the patient's EDTA peripheral blood using the same kit. Written informed consent for the use of material for genetic analyses on tumor and blood was obtained from patients.

\section{Histology}

The pathologic assessment was performed by two boardcertified neuropathologists as described earlier [11]. In brief, the tumor was called oligoastrocytoma if a fibrillary, gemistocytic, or protoplasmatic component was well developed and if at least one high-power field was found in the specimen that, if considered alone, would have warranted diagnosis of an oligodendroglioma. The tumor was considered an oligodendroglioma if this component was exclusive or largely predominant and no astroglial differentiation was present except for the minigemistocytes and gliofibrillary oligodendrocytes frequently present in typical oligodendrogliomas. 
Loss of heterozygosity on $1 \mathrm{p} / 19 \mathrm{q}$

Genotypes for multiple loci were determined by polymerase chain reaction using fluorescent primers tagged with HEX or FAM (Microsynth, Balgach, Switzerland) for microsatellite markers on chromosome 1p36 (D1S468, D1S1612, D1S228, D1S214) and chromosome 19q13 (D19S219, D19S412, D19-HRC). The microsatellite markers spanned over the regions 1p36.21-1p36.33 and 19q13.31-19q13.41 and were selected according to Smith et al. [12]. PCR amplification was performed in separate reactions. Analysis of PCR products was performed by capillary electrophoresis using a genetic analyzer (ABI Prism 3100-Avant; Applied Biosystems, Rotkreuz, Switzerland) and GeneMapper software 4.0. LOH was determined by measuring the peak area from each of the alleles produced from the tumor and corresponding normal DNA. Diagnostic criteria for $\mathrm{LOH}$ required the calculated ratio of the peak areas to be less than 0.5 .

\section{MGMT promoter methylation}

Bisulfite treatment was performed using the EZ DNA modification kit according to the manufacturer's procedure (Zymo, Orange, CA, USA). The modified DNA was eluted with $10 \mu \mathrm{l}$ M-elution buffer and diluted with $10 \mu \mathrm{l}$ water.

Qualitative methylation-specific PCR was performed using primer pairs specific for the methylated (M_forward_HEX and M_rv) or unmethylated (U_forward_FAM and U_rv) form of the MGMT promoter, and $2 \mu \mathrm{l}$ bisulfite-treated DNA. Forward primers were tagged with HEX or FAM (Microsynth). The sequence of the primers used are reported elsewhere [15]. PCR products were analyzed by capillary electrophoresis as described above.

Establishment and validation of the quantitative methylation-specific assay are described elsewhere (Vassella et al. back to back submission). Briefly, bisulfite-treated DNA was amplified by PCR using the primer pair MU_forward (5'-GGATATGTTGGGATAGTT- $\left.{ }^{\prime}\right)$ and MU_rv (5'-ACG CCTACAAAACCACTC- $3^{\prime}$ ) and $2 \mu$ bisulfite-treated DNA. The PCR product was diluted 1:10 with water and subjected to a multiplex primer extension using primers M_forward_HEX and U_forward_FAM. Analysis was performed by capillary electrophoresis. The percentage of methylated DNA was determined by measuring the peak area for methylated and unmethylated DNA and normalized to a control containing equal amounts of methylated and unmethylated DNA, which was performed in the same experiment.

The median of MGMT promoter methylation was used to define the cut off between high and low methylation.
Statistical analysis

Patient and therapy-related factors were tested for a possible correlation with response under TMZ therapy. Fisher's exact test based on cross-tables was performed to test the influence of age ( $<40$ years and $>40$ years), gender, presence of any oligodendroglial component, 1p36 and $19 \mathrm{q} 13$ status, and tumor volume $\left(<70 \mathrm{~cm}^{3}\right.$ and $\left.>70 \mathrm{~cm}^{3}\right)$. Linear regression was used to analyze the interaction of MGMT methylation and volumetric response. KaplanMeier curves were compared using the Log-rank test. The level of statistical significance was set at $P<0.05$ for a two-tailed hypothesis. GraphPad Prism 5 software (San Diego, CA, USA) was used for statistical analysis.

\section{Results}

Patient characteristics

The demographic details of the study cohort are presented in Table 1. There were thirteen males and nine females. The median age was 53 years. All patients had histological confirmation of grade II gliomas (ten oligodendrogliomas, seven oligoastrocytomas, and five astrocytomas). Median time from diagnosis to treatment with TMZ was 59.6 months (range 2-220 months). Seven patients underwent prior subtotal resection, six patients had prior radiotherapy, but none of the patients had received chemotherapy before. All patients demonstrated evidence of neurological progression. This included seizure exacerbation in 18 patients, aphasia in seven patients, cognitive decline in nine patients, paralysis in one patient, and vertigo in one patient.

All patients received TMZ chemotherapy $200 \mathrm{mg} / \mathrm{m}^{2}$ on days $1-5$ in a 28 days cycle. The median duration of TMZ treatment was 12 months. Seven patients were changed to a dose-dense TMZ scheme (14/21 days $\left.100 \mathrm{mg} / \mathrm{m}^{2}\right)$ after progression. Two of these seven patients had a radiological MR. Seventeen of the 22 patients did not receive steroids at any time during TMZ treatment. Of the remaining five patients, three had a stable dose and steroids could be reduced in two patients during TMZ treatment.

\section{Toxicity}

Generally, TMZ was well tolerated. Adverse events are listed in Table 2. Major toxicity was limited to myelosuppression. Two patients experienced grade 3-4 leucopenia and five patients grade 3-4 thrombocytopenia. Non-hematological adverse events were mild (grade 1-2). 
Table 1 Patient characteristics

\begin{tabular}{|c|c|c|}
\hline & Number & $\%$ \\
\hline No. of patients & 22 & \\
\hline \multicolumn{3}{|l|}{ Gender } \\
\hline Male & 13 & 59 \\
\hline Female & 9 & 41 \\
\hline \multicolumn{3}{|l|}{ Age, years } \\
\hline Median & 53 & \\
\hline Range & $27-72$ & \\
\hline \multicolumn{3}{|l|}{$\begin{array}{l}\text { Time from biopsy to } \\
\text { treatment (month) }\end{array}$} \\
\hline Median & 4.5 & \\
\hline Range & $1-148$ & \\
\hline \multicolumn{3}{|l|}{ Histology } \\
\hline Oligodendroglioma & 10 & 45 \\
\hline Oligoastrocytoma & 7 & 32 \\
\hline Astrocytoma & 5 & 23 \\
\hline \multicolumn{3}{|l|}{ Prior surgery } \\
\hline Biopsy only & 15 & 68 \\
\hline Subtotal resection & 7 & 32 \\
\hline Prior radiotherapy & 6 & 27 \\
\hline \multicolumn{3}{|l|}{ Tumor volume $\left(\mathrm{cm}^{3}\right)$} \\
\hline Median & 69.7 & \\
\hline Range & $21-332$ & \\
\hline \multicolumn{3}{|l|}{ Side } \\
\hline Left & 14 & 63 \\
\hline Right & 7 & 32 \\
\hline Right and left & 1 & 5 \\
\hline \multicolumn{3}{|l|}{ Tumor location } \\
\hline Frontal lobe & 9 & 41 \\
\hline Insula & 1 & 5 \\
\hline Temporal lobe & 4 & 18 \\
\hline Parietal lobe & 8 & 36 \\
\hline \multicolumn{3}{|l|}{ Clinical symptoms } \\
\hline Seizure & 18 & 82 \\
\hline Aphasia & 7 & 32 \\
\hline Cognitive deficiency & 9 & 41 \\
\hline Paralysis & 1 & 5 \\
\hline Vertigo & 1 & 5 \\
\hline \multicolumn{3}{|l|}{$\begin{array}{l}\text { WHO PS at start } \\
\text { of treatment }\end{array}$} \\
\hline Median & 0 & \\
\hline Range & $0-2$ & \\
\hline \multicolumn{3}{|l|}{ Cycles of TMZ } \\
\hline Median & 12 & \\
\hline Range & $4-22$ & \\
\hline \multicolumn{3}{|l|}{ TMZ regimen (pts) } \\
\hline Day $1-5$ & 22 & 100 \\
\hline Dose dense & 7 & 32 \\
\hline
\end{tabular}

Table 2 Toxicity

\begin{tabular}{|c|c|c|c|c|}
\hline \multirow[b]{2}{*}{ Event } & \multicolumn{2}{|l|}{ Grades $1-2$} & \multicolumn{2}{|l|}{ Grades 3-4 } \\
\hline & No of patients & $\%$ & No of patients & $\%$ \\
\hline \multicolumn{5}{|l|}{ Blood/bone marrow } \\
\hline Anemia & 13 & 59 & & \\
\hline Leucopenia & 9 & 41 & 2 & 9 \\
\hline Thrombocytopenia & 3 & 14 & 5 & 23 \\
\hline \multicolumn{5}{|l|}{ Laboratory } \\
\hline ALT/AST & 1 & 5 & & \\
\hline Bilirubin & 2 & 9 & & \\
\hline Glucose & 6 & 27 & & \\
\hline Hyponatremia & 1 & 5 & & \\
\hline Hypernatremia & 5 & 23 & & \\
\hline \multicolumn{5}{|l|}{ Gastrointestinal } \\
\hline Nausea/vomiting & 14 & 64 & & \\
\hline Constipation & 9 & 41 & & \\
\hline \multicolumn{5}{|l|}{ Others } \\
\hline Mucositis & 2 & 9 & & \\
\hline Rash/desquamation & 2 & 9 & & \\
\hline
\end{tabular}

Treatment outcome

Median progression-free survival of the study cohort was 32 month (95\% CI, 8.1-52.6). Progression was defined as increase in tumor volume of $>25 \%$. Twelve of the 22 patients showed signs of contrast enhancement at the time of volumetric progression (55\%). Progression-free survival (PFS) at 12 and 24 months was 81 and $61 \%$, respectively (Fig. 1a). From the start of treatment with TMZ median overall survival was 50 month (95\% CI, 18.5-77.3, Fig. 1b). Neither PFS nor OS differed significantly by tumor type (Fig. 1c, d).

Marked clinical improvement was documented in 14 patients $(64 \%)$. Clinical stability was reported in eight patients $(36 \%)$. None of the patients demonstrated evidence of neurological progression during treatment.

The objective response rate by MRI criteria was $59 \%$ (6 PRs and $7 \mathrm{MRs}$ ). Eight patients maintained stable disease (SD), and one patient developed progressive disease (PD). An example of the radiological tumor analysis for a responding patient is shown in Fig. 2 a, b. Consecutive areas were used to calculate the volume. There was no significant association between age ( $<40$ years and $>40$ years, $P=0.617)$, gender $(P=$ $0.674)$, prior radiation $(P=0.411)$ presence of any oligodendroglial component $(P=0.609)$, tumor volume $\left(<70 \mathrm{~cm}^{3}\right.$ and $\left.>70 \mathrm{~cm}^{3}, P=1.000\right)$, and radiological response. The median best volumetric change during 
Fig. 1 Progression free and overall survival. a PFS for all patients $(n=22)$. b OS for all patients $(n=22)$. $\mathbf{c}$ PFS and d OS separated by tumor type oligodendrogloma $(\mathrm{OD}$, $n=10)$, oligoastrocytoma (OA, $n=7)$, and pure astrocytoma (A, $n=5)$. MRI were performed before therapy and every six months thereafter. Progressive disease was defined as an increase in tumor volume by $\geq 25 \%$, independent of contrast enhancement. $(\perp$ censored event)

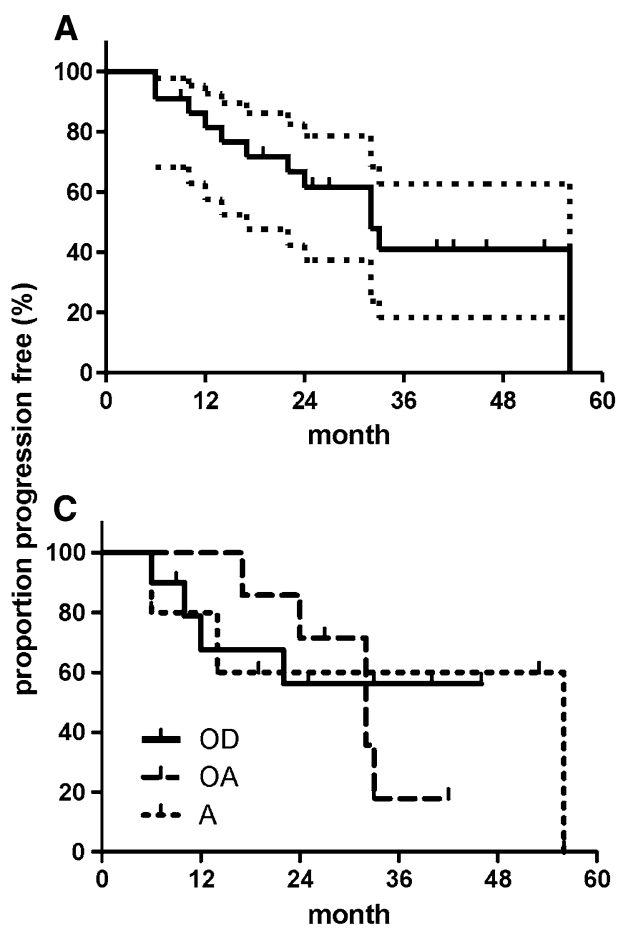

therapy with TMZ was a $25.5 \%$ reduction in tumor volume compared with pre-treatment MRI. Patients with a good radiological response ( $>25.5 \%$ reduction) had improved progression-free survival compared with patients with poor radiological response $(<25.5 \%$ reduction; Fig. 4a, HR 0.14 ; 95\% CI $0.04-0.53, P=0.004)$.

\section{LOH status of $1 p / 19 q$ and treatment outcome}

Twenty tumor and blood DNA pairs were available for $1 \mathrm{p} / 19 \mathrm{q}$ LOH analysis (Fig. 2). LOH on both $1 \mathrm{p}$ and $19 \mathrm{q}$ was detected in 14 patients (64\%). A radiographic response was observed for eight of those patients (4 PRs and 4 MRs), five patients maintained SD, and one patient progressed. Two patients had either LOH 1p or 19q only. Both had an MR under TMZ treatment. One of the remaining four patients with intact $1 p$ and $19 q$ had a PR; for the other three patients SD was the maximum response. There was no significant association between $1 \mathrm{p} \mathrm{LOH}$ and radiographic response $(P=0.303$, not shown). However, time to radiological progression was significantly longer for patients with $\mathrm{LOH} 1 \mathrm{p}$ and/or $19 \mathrm{q}$ than for patients with intact chromosomes $1 \mathrm{p}$ and $19 \mathrm{q}$ in their tumor (Fig. 4b; HR $0.11 ; 95 \%$ CI $0.01-0.90, P=0.039$ ).

MGMT promoter methylation and tumor response

Methylation-specific PCR was performed for all tumor samples. MGMT promoter methylation was detectable in 19 patients by conventional PCR. For two patients with negative MGMT promoter methylation SD was their maximum response; one patient had an MR. The association between MGMT promoter methylation and radiographic response did not reach statistical significance $(P=0.544$, not shown).

Quantitative analysis of MGMT promoter methylation revealed methylation levels between 12 and $100 \%$. The three tumor samples that were negative in conventional methylation-specific PCR similarly revealed $0 \%$ methylation in the quantitative assay. We next analyzed the correlation between the level of MGMT promoter methylation and volumetric response to chemotherapy after 6 months and at the time point of maximum response as a continuous variable. The level of MGMT methylation correlated with radiographic response after 6 months of therapy $(P=$ 0.012 , Fig. 3a) and with maximum response to chemotherapy $(P=0.045$, Fig. 3b).

The median MGMT promoter methylation level in the 22 patients analyzed was $75 \%$. Patients with high MGMT promoter methylation levels $(>75 \%)$ had a significantly longer time to progression than patients with methylation levels below 75\% (HR 0.20, 95\% CI 0.06-0.70, $P=0.012$, Fig. 4c).

\section{Discussion}

There is increasing evidence that chemotherapeutic agents used for treatment of high-grade gliomas, for example PCV or TMZ, are also active against low-grade glioma in adults 

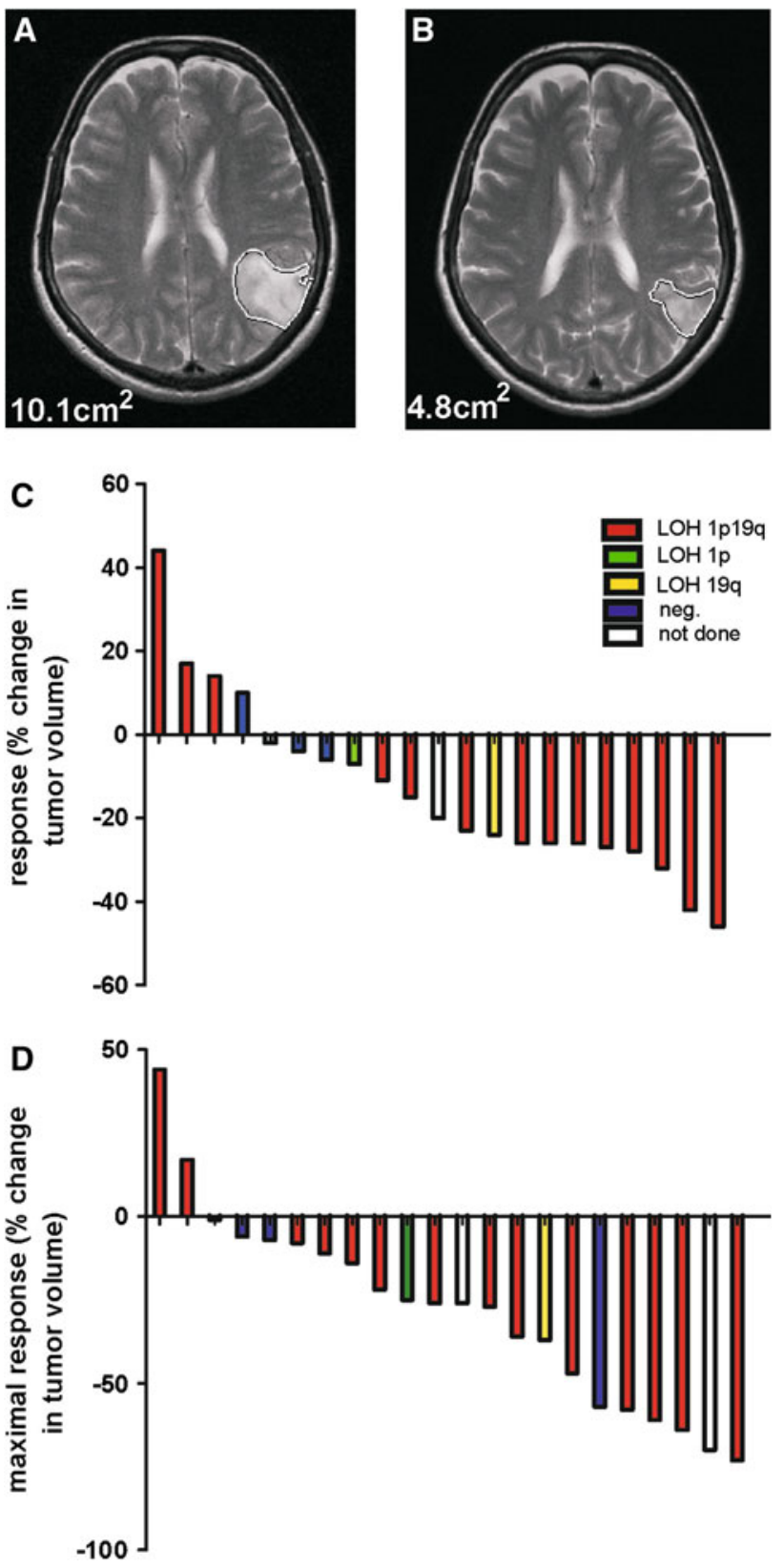

Fig. 2 Radiological response of low-grade glioma. The volumetric response in MRI was analyzed every 6 months on the basis of the entire region of hyperintensity (compared with normal brain) in T2weighted and FLAIR MRIs and compared with the volume before treatment. One example of the area analysis in T2-weighted MRI before (a) and after treatment is shown (b). Forest plot of the dependence of radiological response on $\mathrm{LOH} 1 \mathrm{q}$ and/or $19 \mathrm{p}$ (c) after 6 months of treatment and (d) maximum response. LOH 1p and 19q were analyzed from tissue samples at diagnosis

[6-10, 19]. This is confirmed in our study-a clinical improvement in 64\% and a radiological response in 59\% (PRs and MRs) of treated patients, with good tolerability. The median PFS was 32 months and compares favorably with published studies of TMZ in low-grade gliomas, in which the median PFS ranged from 10 to 31 months
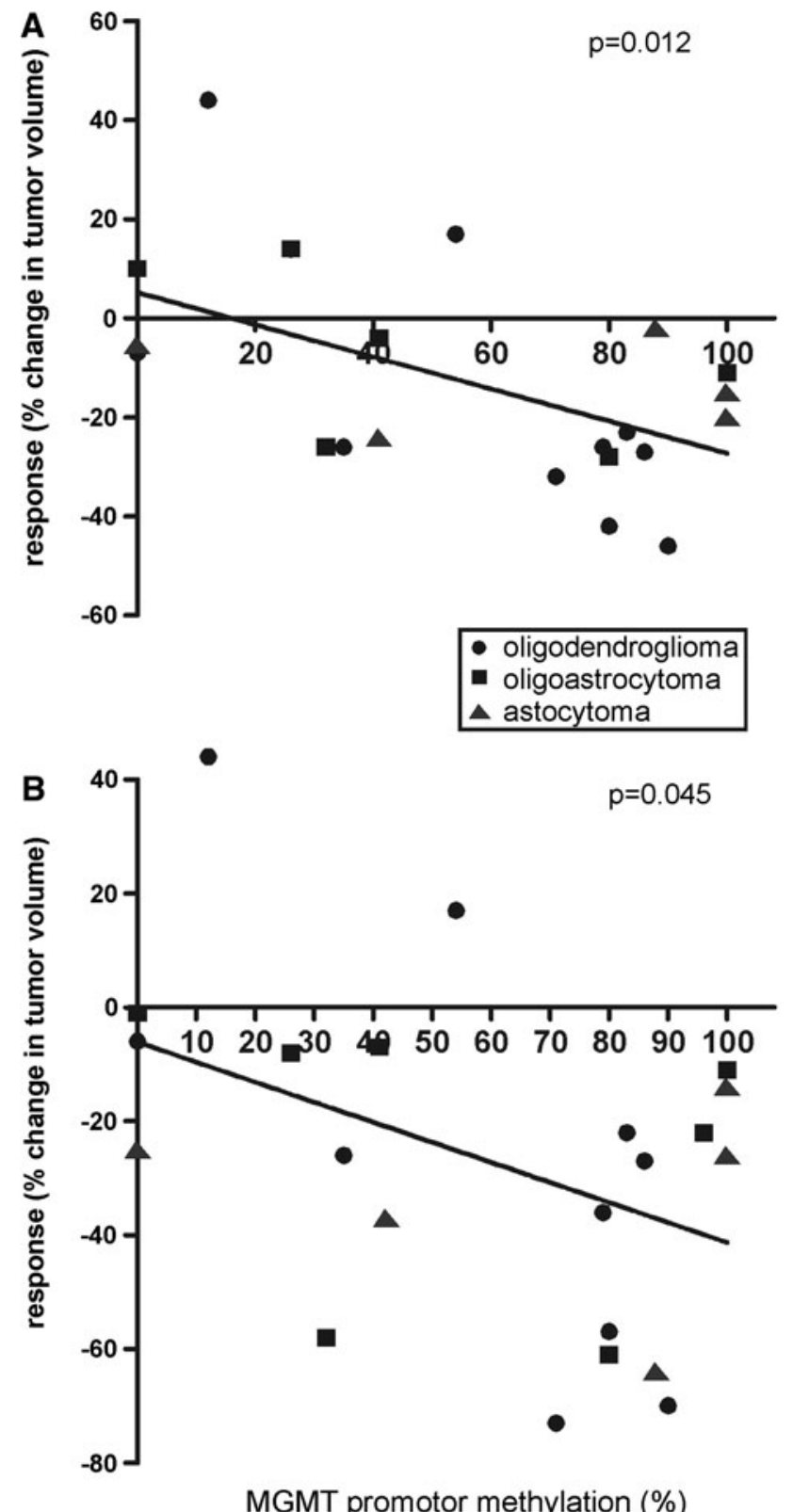

Fig. 3 Correlation of MGMT promoter methylation and radiological response (a) after 6 months of treatment and (b) maximum response. Quantitative MGMT promoter methylation was analyzed as described by Vasella et al. (accompanying manuscript) from tissue samples at diagnosis. The volumetric response in MRI was analyzed every 6 months on the basis of the entire region of hyperintensity (compared with normal brain) in T2-weighted and FLAIR MRIs and compared with the volume before treatment

$[6,7,20,21]$. This may largely reflect the selection of good prognostic patients in our study. Recently, Kesari et al. showed in a prospective phase II study that protracted daily TMZ ( 7 weeks on/4 weeks off) results in a radiological response rate of $20 \%$ (PR) and a median PFS of 38 month [22]. These promising results may be the consequence of increased dose density of protracted daily TMZ versus 

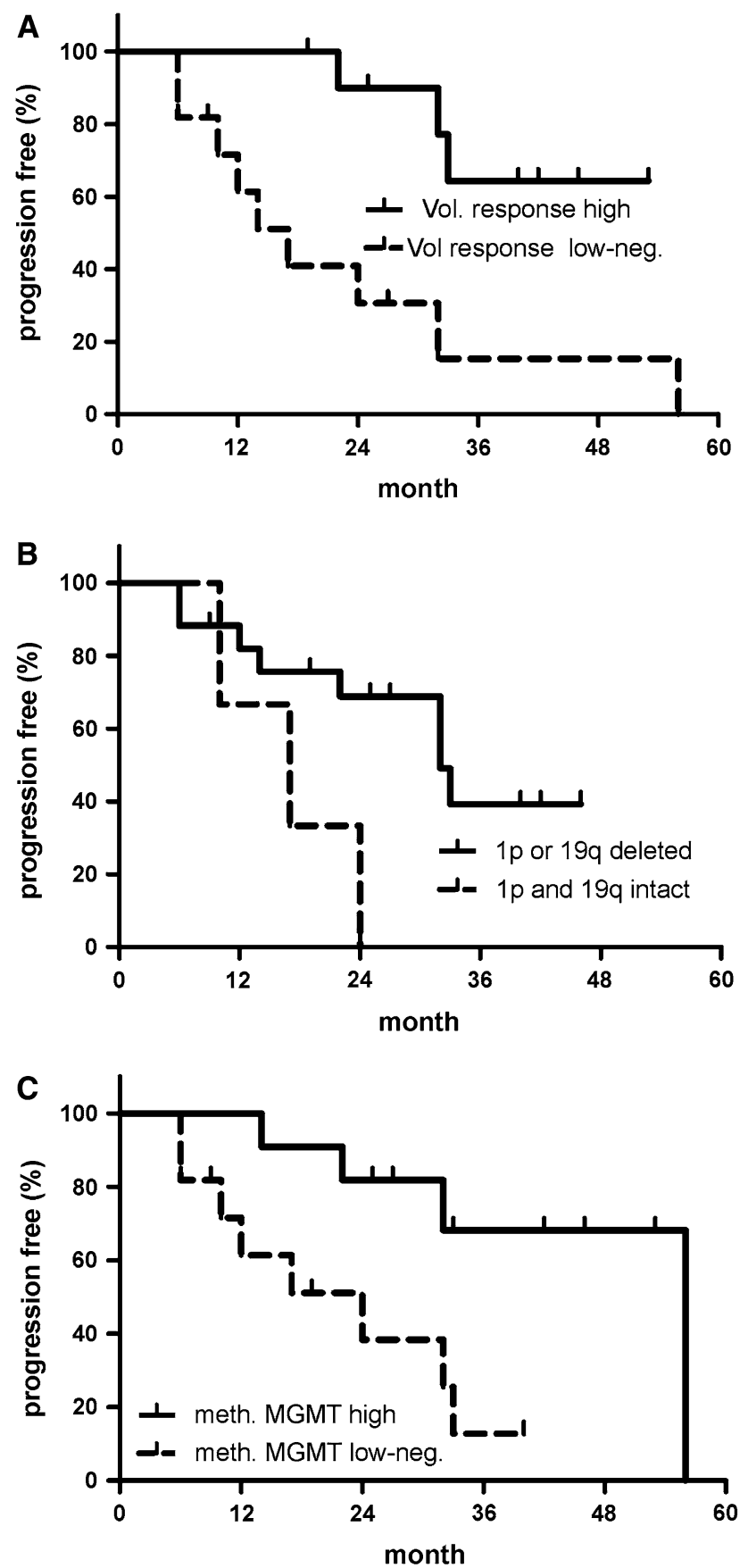

Fig. 4 Volumetric response, $1 p$ and $19 q$ deletion status, and MGMT promoter methylation level and PFS. a PFS of patients were separated into a group with a radiological response better than the median reduction of $25.5 \%$ (vol. response high, $n=11$ ) and a group of patients with poor radiological response (below $25.5 \%$ reduction in tumor volume (vol. response low-neg, $n=11$; log rank $P=0.004$ ). b PFS for patients with $1 \mathrm{p}$ and/or $19 \mathrm{q}$ deletion $(n=17)$ and patients with intact $1 \mathrm{p}$ and $19 \mathrm{q}(n=3$; $\log$ rank $P=0.039)$. (c) PFS for patients with a high level of MGMT promoter methylation $(>75 \%=$ median, $n=11$ ) and patients with low or negative MGMT promoter methylation level $(n=11, \log \operatorname{rank} P=0.012)(\perp$ denotes a censored event) standard 5 day TMZ or, potentially, of MGMT depletion in the tumor during continuous exposure to TMZ [23].

Although published studies and our own retrospective study confirm the clinical efficacy of TMZ in low-grade gliomas, it remains open how to incorporate chemotherapy in the treatment algorithm of these tumors. Currently, chemotherapy is primarily used for recurrent disease. The role of chemotherapy in the initial management of low-grade gliomas is under investigation in several large ongoing studies. Identification of patients who benefit from treatment has a major impact on patient care. Several predictive factors for the response to chemotherapy have been identified in gliomas. These include histological characteristics such as oligo-component versus non-oligo tumors, and molecular profiles such as LOH on $1 \mathrm{p} / 19 \mathrm{q}$ and MGMT promoter methylation [9, 10, 24]. Of note, most of these characteristics were defined in retrospective analysis and are not strictly predictive of the response under chemotherapy but are also prognostic, independent of the treatment [11, 12]. Other genetic factors such as IDH1 mutation may be prognostic but not predictive for response to TMZ [25].

In this study we correlated known predictive and prognostic molecular markers with radiological response. Our series clearly indicates selection by histological characteristics, resulting in $77 \%$ tumors with an oligodendroglial component. This also explains the high frequency of $\mathrm{LOH}$ on $1 \mathrm{p}$ and/or $19 \mathrm{q}$, which was found in $82 \%$ of the tumors analyzed [26]. Similarly, MGMT promoter methylation was found in $86 \%$ of the tumor samples analyzed, which is also higher than would be expected in an unselected population of patients with low-grade gliomas. Whether or not MGMT promoter methylation and $\mathrm{LOH}$ status are causally linked or MGMT promoter methylation is an independent predictive marker for WHO grade II gliomas is controversial [26-28].

As a consequence of the limited sample size and the selection of oligo-tumors in our study, histological features could not be validated as predictive markers. Our data confirmed for low-grade glioma that patients with LOH1p/ $19 \mathrm{q}$ in the tumor clearly have longer progression-free survival than patients with tumors with intact $1 \mathrm{p} / 19 \mathrm{q}$. In contrast, $\mathrm{LOH} 1 \mathrm{p}$ and $19 \mathrm{q}$ was not correlated with radiological response to TMZ treatment. However, although our study selected for patients with good prognostic and probably predictive markers for the treatment with TMZ, treatment outcome varied substantially within this group. This finding underscores the need for additional biomarkers able to predict the level of response to TMZ. Although each tumor cell has a defined quantity of MGMT protein, the level can vary substantially within a tumor. MGMT stoichiometrically removes TMZ-induced methylation adducts from guanine residues [29]. Therefore, the effect of MGMT depends on 
the level of expression within a tumor cell and on the heterogeneity of the tumor. In fact, a recent study in gliobloastoma showed that the degree of promoter methylation as analyzed by pyrosequencing correlates with progressionfree and overall survival [30]. We have now quantitatively analyzed the level of methylation of the MGMT promoter in our tumor samples of low-grade gliomas. The volumetric response to chemotherapy correlated with the level of MGMT promoter methylation. In addition, time to progression was significantly longer in the group with high level of MGMT promoter methylation than in the group with low level MGMT promoter methylation. Molecular analysis was performed on tissue samples taken at diagnosis, which is 1-148 months (median 4.5 months, Table 1) before the start of treatment with TMZ. However, none of the patients received alkylating agents before treatment with TMZ. In addition, currently there is no indication that MGMT promoter methylation varies over time in the absence of chemotherapy. Therefore, our data suggest that the level of MGMT promoter methylation at diagnosis can serve as a predictive marker for a therapy that is applied several months later. In summary, our data indicate that in tumors with MGMT promoter methylation, quantitative analysis of the level of methylation enables further prediction of the magnitude of response and time to progression.

\section{References}

1. van den Bent MJ, Afra D, de Witte O, Ben Hassel M, Schraub S, Hoang-Xuan K, Malmstrom PO, Collette L, Pierart M, Mirimanoff R, Karim AB (2005) Long-term efficacy of early versus delayed radiotherapy for low-grade astrocytoma and oligodendroglioma in adults: the EORTC 22845 randomised trial. Lancet 366:985-990

2. Karim AB, Maat B, Hatlevoll R, Menten J, Rutten EH, Thomas DG, Mascarenhas F, Horiot JC, Parvinen LM, van Reijn M, Jager JJ, Fabrini MG, van Alphen AM, Hamers HP, Gaspar L, Noordman E, Pierart M, van Glabbeke M (1996) A randomized trial on dose-response in radiation therapy of low-grade cerebral glioma: European Organization for Research and Treatment of Cancer (EORTC) Study 22844. Int J Radiat Oncol Biol Phys 36:549-556

3. Shaw E, Arusell R, Scheithauer B, O'Fallon J, O'Neill B, Dinapoli R, Nelson D, Earle J, Jones C, Cascino T, Nichols D, Ivnik R, Hellman R, Curran W, Abrams R (2002) Prospective randomized trial of low- versus high-dose radiation therapy in adults with supratentorial low-grade glioma: initial report of a North Central Cancer Treatment Group/Radiation Therapy Oncology Group/Eastern Cooperative Oncology Group study. J Clin Oncol 20:2267-2276

4. Correa DD, De Angelis LM, Shi W, Thaler HT, Lin M, Abrey LE (2007) Cognitive functions in low-grade gliomas: disease and treatment effects. J Neurooncol 81:175-184

5. Stupp R, Janzer RC, Hegi ME, Villemure JG, Mirimanoff RO (2003) Prognostic factors for low-grade gliomas. Semin Oncol $30: 23-28$
6. Pace A, Vidiri A, Galie E, Carosi M, Telera S, Cianciulli AM, Canalini P, Giannarelli D, Jandolo B, Carapella CM (2003) Temozolomide chemotherapy for progressive low-grade glioma: clinical benefits and radiological response. Ann Oncol 14: 1722-1726

7. Quinn JA, Reardon DA, Friedman AH, Rich JN, Sampson JH, Provenzale JM, McLendon RE, Gururangan S, Bigner DD, Herndon JE II, Avgeropoulos N, Finlay J, Tourt-Uhlig S, Affronti ML, Evans B, Stafford-Fox V, Zaknoen S, Friedman HS (2003) Phase II trial of temozolomide in patients with progressive lowgrade glioma. J Clin Oncol 21:646-651

8. Brada M, Viviers L, Abson C, Hines F, Britton J, Ashley S, Sardell S, Traish D, Gonsalves A, Wilkins P, Westbury C (2003) Phase II study of primary temozolomide chemotherapy in patients with WHO grade II gliomas. Ann Oncol 14:1715-1721

9. Hoang-Xuan K, Capelle L, Kujas M, Taillibert S, Duffau H, Lejeune J, Polivka M, Criniere E, Marie Y, Mokhtari K, Carpentier AF, Laigle F, Simon JM, Cornu P, Broet P, Sanson M, Delattre JY (2004) Temozolomide as initial treatment for adults with low-grade oligodendrogliomas or oligoastrocytomas and correlation with chromosome $1 \mathrm{p}$ deletions. J Clin Oncol 22: 3133-3138

10. Kaloshi G, Benouaich-Amiel A, Diakite F, Taillibert S, Lejeune J, Laigle-Donadey F, Renard MA, Iraqi W, Idbaih A, Paris S, Capelle L, Duffau H, Cornu P, Simon JM, Mokhtari K, Polivka M, Omuro A, Carpentier A, Sanson M, Delattre JY, Hoang-Xuan K (2007) Temozolomide for low-grade gliomas: predictive impact of 1p/19q loss on response and outcome. Neurology 68: $1831-1836$

11. Mariani L, Deiana G, Vassella E, Fathi AR, Murtin C, Arnold M, Vajtai I, Weis J, Siegenthaler P, Schobesberger M, Reinert MM (2006) Loss of heterozygosity $1 \mathrm{p} 36$ and $19 \mathrm{q} 13$ is a prognostic factor for overall survival in patients with diffuse WHO grade 2 gliomas treated without chemotherapy. J Clin Oncol 24: $4758-4763$

12. Smith JS, Perry A, Borell TJ, Lee HK, O'Fallon J, Hosek SM, Kimmel D, Yates A, Burger PC, Scheithauer BW, Jenkins RB (2000) Alterations of chromosome arms $1 p$ and $19 q$ as predictors of survival in oligodendrogliomas, astrocytomas, and mixed oligoastrocytomas. J Clin Oncol 18:636-645

13. Newlands ES, Stevens MF, Wedge SR, Wheelhouse RT, Brock C (1997) Temozolomide: a review of its discovery, chemical properties, pre-clinical development and clinical trials. Cancer Treat Rev 23:35-61

14. Esteller M, Garcia-Foncillas J, Andion E, Goodman SN, Hidalgo OF, Vanaclocha V, Baylin SB, Herman JG (2000) Inactivation of the DNA-repair gene MGMT and the clinical response of gliomas to alkylating agents. N Engl J Med 343:1350-1354

15. Hegi ME, Diserens AC, Gorlia T, Hamou MF, de Tribolet N, Weller M, Kros JM, Hainfellner JA, Mason W, Mariani L, Bromberg JE, Hau P, Mirimanoff RO, Cairncross JG, Janzer RC, Stupp R (2005) MGMT gene silencing and benefit from temozolomide in glioblastoma. N Engl J Med 352:997-1003

16. Rivera AL, Pelloski CE, Gilbert MR, Colman H, De La Cruz C, Sulman EP, Bekele BN, Aldape KD (2010) MGMT promoter methylation is predictive of response to radiotherapy and prognostic in the absence of adjuvant alkylating chemotherapy for glioblastoma. Neuro Oncol 12:116-121

17. Colman H, Zhang L, Sulman EP, McDonald JM, Shooshtari NL, Rivera A, Popoff S, Nutt CL, Louis DN, Cairncross JG, Gilbert MR, Phillips HS, Mehta MP, Chakravarti A, Pelloski CE, Bhat K, Feuerstein BG, Jenkins RB, Aldape K (2010) A multigene predictor of outcome in glioblastoma. Neuro Oncol 12:49-57

18. Preusser M (2009) MGMT analysis at DNA, RNA and protein levels in glioblastoma tissue. Histol Histopathol 24:511-518 
19. Levin N, Lavon I, Zelikovitsh B, Fuchs D, Bokstein F, Fellig Y, Siegal T (2006) Progressive low-grade oligodendrogliomas: response to temozolomide and correlation between genetic profile and O6-methylguanine DNA methyltransferase protein expression. Cancer 106:1759-1765

20. van den Bent MJ, Taphoorn MJ, Brandes AA, Menten J, Stupp R, Frenay M, Chinot O, Kros JM, van der Rijt CC, Vecht Ch J, Allgeier A, Gorlia T (2003) Phase II study of first-line chemotherapy with temozolomide in recurrent oligodendroglial tumors: the European Organization for Research and Treatment of Cancer Brain Tumor Group Study 26971. J Clin Oncol 21:2525-2528

21. Pouratian N, Gasco J, Sherman JH, Shaffrey ME, Schiff D (2007) Toxicity and efficacy of protracted low dose temozolomide for the treatment of low grade gliomas. J Neurooncol 82:281-288

22. Kesari S, Schiff D, Drappatz J, LaFrankie D, Doherty L, Macklin EA, Muzikansky A, Santagata S, Ligon KL, Norden AD, Ciampa A, Bradshaw J, Levy B, Radakovic G, Ramakrishna N, Black PM, Wen PY (2009) Phase II study of protracted daily temozolomide for low-grade gliomas in adults. Clin Cancer Res 15: 330-337

23. Kreklau EL, Kurpad C, Williams DA, Erickson LC (1999) Prolonged inhibition of $\mathrm{O}(6)$-methylguanine DNA methyltransferase in human tumor cells by $\mathrm{O}(6)$-benzylguanine in vitro and in vivo. J Pharmacol Exp Ther 291:1269-1275

24. Hegi ME, Murat A, Lambiv WL, Stupp R (2006) Brain tumors: molecular biology and targeted therapies. Ann Oncol 17(suppl 10): x191-x197

25. Dubbink HJ, Taal W, van Marion R, Kros JM, van Heuvel I, Bromberg JE, Zonnenberg BA, Zonnenberg CB, Postma TJ,
Gijtenbeek JM, Boogerd W, Groenendijk FH, Smitt PA, Dinjens WN, van den Bent MJ (2009) IDH1 mutations in low-grade astrocytomas predict survival but not response to temozolomide. Neurology 73:1792-1795

26. Watanabe T, Nakamura M, Kros JM, Burkhard C, Yonekawa Y, Kleihues P, Ohgaki H (2002) Phenotype versus genotype correlation in oligodendrogliomas and low-grade diffuse astrocytomas. Acta Neuropathol 103:267-275

27. Everhard S, Kaloshi G, Criniere E, Benouaich-Amiel A, Lejeune J, Marie Y, Sanson M, Kujas M, Mokhtari K, Hoang-Xuan K, Delattre JY, Thillet J (2006) MGMT methylation: a marker of response to temozolomide in low-grade gliomas. Ann Neurol 60: 740-743

28. Mollemann M, Wolter M, Felsberg J, Collins VP, Reifenberger G (2005) Frequent promoter hypermethylation and low expression of the MGMT gene in oligodendroglial tumors. Int J Cancer 113: 379-385

29. Sharma S, Salehi F, Scheithauer BW, Rotondo F, Syro LV, Kovacs K (2009) Role of MGMT in tumor development, progression, diagnosis, treatment and prognosis. Anticancer Res 29: 3759-3768

30. Dunn J, Baborie A, Alam F, Joyce K, Moxham M, Sibson R, Crooks D, Husband D, Shenoy A, Brodbelt A, Wong H, Liloglou T, Haylock B, Walker C (2009) Extent of MGMT promoter methylation correlates with outcome in glioblastomas given temozolomide and radiotherapy. Br J Cancer 101:124-131 